\title{
An Analytical Modeling Approach for Performance Evaluation of Electrostatic Precipitator (ESP)
}

\author{
Shanti Faridah Salleh ${ }^{1 *}$, Afrasyab Khan ${ }^{2}$, Cirilo Nolasco Hipolito ${ }^{1}$, Lennevey Kinidi ${ }^{1}$, Dayang Siti Herdawati \\ Abang Hardin ${ }^{1}$ \\ ${ }^{1}$ Faculty of Engineering, Department of Chemical Engineering \& Energy Sustainability, University Malaysia \\ Sarawak (UNIMAS), P.O. Box: 94300, Kota Samarahan, Sarawak, Malaysia \\ ${ }^{2}$ Faculty of Engineering, Department of Mechanical \& Manufacturing Engineering, University Malaysia \\ Sarawak (UNIMAS), P.O. Box: 94300, Kota Samarahan, Sarawak, Malaysia
}

*Corresponding author: sshanti@unimas.my

Article History

Received: October 30, 2018 Received in revised form: December 13, 2018 Accepted: December 27, 2018 Published Online: February 10, 2019

\begin{abstract}
A coal-fired flue gas contains high concentrations of fine particles which can pose a threat to the environment. In this study, an electrostatic precipitator is used to remove the fine particles of the flue gas from a $100 \mathrm{MW}$ coal fired power plant by using a model. A model has been presented to estimate the performance of the wet electrostatic precipitator (WEP) in terms of the number of plates, flow rates and velocity. The equations have been specified for the charging and charge on the single particle of some definite diameter. The effect of the measuring points for the calculation of the effective migration velocities and hence overall performance along with the re-entrainment and gas sneakage have been incorporated. Ranges for the above-mentioned parameters are well defined and it has been observed that after a certain range values across number of plates, velocities and flow rates there is no significant improvement in the performance of the WEP has been calculated.
\end{abstract}

Keywords: Wet electrostatic precipitator; flow; collection; efficiency; performance.

\subsection{INTRODUCTION}

The health risks and environmental issues related to the emission of fine particles in coal-fired power plants can be controlled by using a commercially available electrostatic precipitator. Electrostatic precipitator is an environmental control device for removing fine particles from large volume flow such as flue gas from power plant to comply the low emission standards prescribed by environmental legislation. The three main goals that should be achieved for the effective electrostatic precipitation are particle charging, collection and particle removal. Electric field furnish the purpose for charging the particles. These charged particles will then migrate towards the plates. The collected charged particles are removed from the collection electrodes using the hammer or water. These two removal mechanisms actually give us the two basic types of the electrostatic precipitator namely, dry and wet electrostatic precipitators. The hammering is done by applying a force on the top of the collection plate using hammer. Besides certain disadvantages like the re-entrainment of the particles the 2 hammering still be capable to give us a huge amount of collection particles attached with these electrodes. The collected particles are removed by using the removal transport system such as hover or convey belt. The objective of this paper was to investigate the removal efficiency of the electrostatic precipitator of the flue gas from a 100MW coal fired power plant by varying the number of plates, gas flow rates and velocities by using a model. 


\subsection{METHODOLOGY}

\subsection{System Description}

A general layout of the ESP with multiple configurations is shown in the Figures 1, 2, 3 and 4 and the typical design parameter of ESP are tabulated on Table 1.

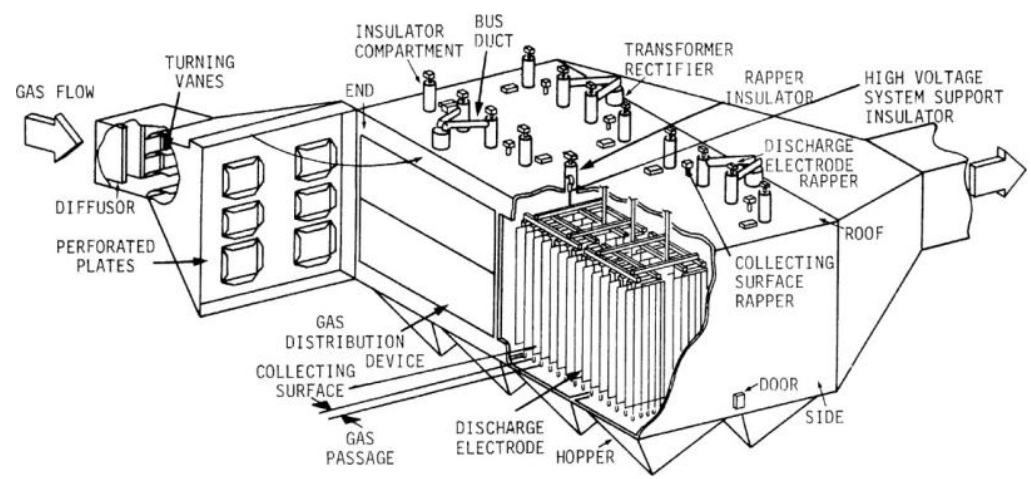

Figure 1. General Layout of the Electrostatic Precipitator (ESP) [1]

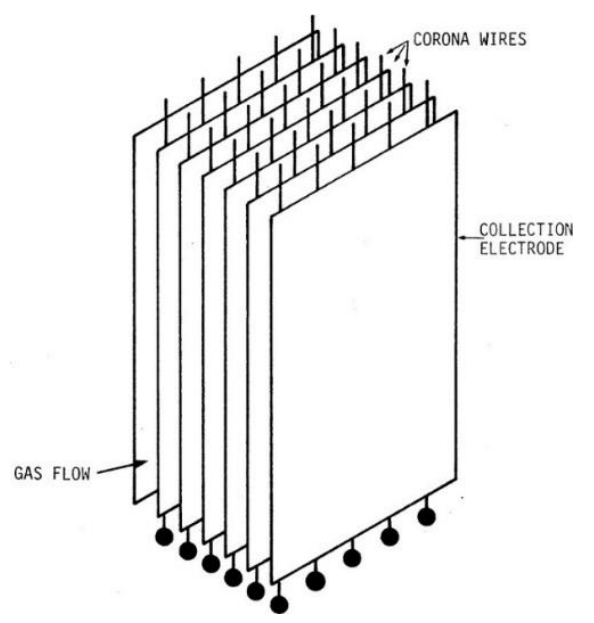

Figure 2. Parallel Plate Electrostatic Precipitator (ESP) [1]

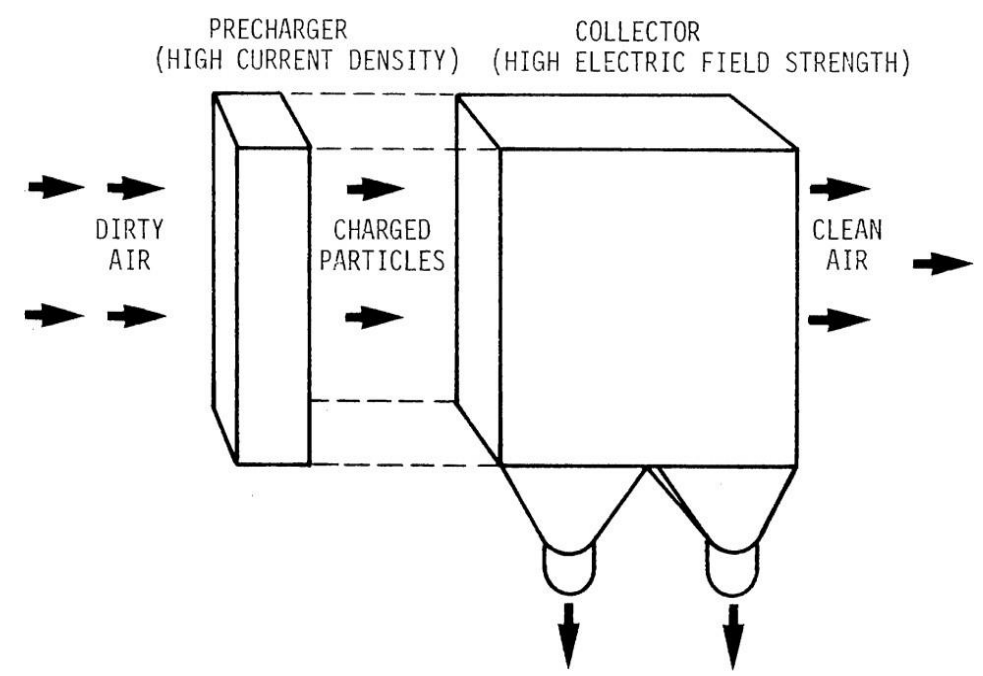

Figure 3. Two Stage Electrostatic Precipitator (ESP) [1] 


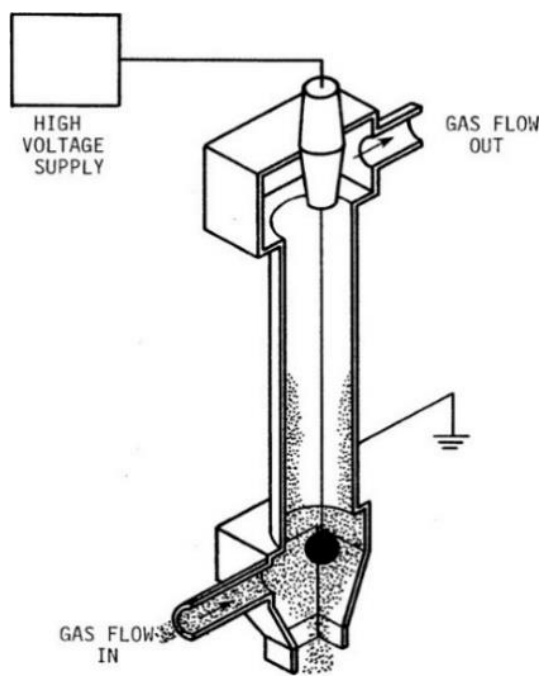

Figure 4. Concept of curved channel + wire configuration of Electro-Static Precipitator (ESP) [1]

Table 1. Typical Design Parameters of ESP on Coal Fired Utility Boiler

\begin{tabular}{|c|c|c|}
\hline \multicolumn{3}{|c|}{ TYPICAL DESIGN PARAMETERS FOR AN ESP ON A COAL FIRED } \\
UTILITY BOILER \\
\hline Sr. No: & PARAMETER & RANGE/VALUE \\
\hline $\mathbf{0 1}$ & Gas Temperature & $340-4000 \mathrm{C}$ \\
\hline $\mathbf{0 2}$ & Overall Collection Efficiency & $99-99.7 \%$ \\
\hline $\mathbf{0 3}$ & Collection Area & $1400 \mathrm{~m} 2$ \\
\hline $\mathbf{0 4}$ & Specific Collection Area & $0.7-1.0 \mathrm{~m} 2 / \mathrm{Am} 3 / \mathrm{min}$ \\
\hline $\mathbf{0 5}$ & Migration Velocity & $0.6-1.8 \mathrm{~cm} / \mathrm{sec}$ \\
\hline $\mathbf{0 6}$ & Gas Vec \\
\hline $\mathbf{0 7}$ & Residence time & $6 \mathrm{sec}$ \\
\hline $\mathbf{0 8}$ & Base operating voltage & $60-30$ \\
\hline
\end{tabular}

\subsection{Model Description}

The theoretical performance of the electrostatic precipitator can be calculated the charge caontained in each particle when charged by utilizing the electric field connected insise the electrostatic precipitator. Particle charge is a component of particle size, retention time, and precipitator working conditions. Estimation of particle charge for diameters surpassing $2.0 \mu \mathrm{m}$ is moderately direct if the working condition of precipitator are sufficiently defined. For diameter of particle less than $2.0 \mu \mathrm{m}$, the estimation of particle charge is intricate. Smith and Mc-Donald has been discussed in paper related to theory of particle charging and the current used expression and model is shown in differential form [2]:

$$
\frac{d q}{d t}=\frac{\text { Noebqo }}{4 \in o}\left(1-\frac{9}{q s}\right)^{2}+\pi r^{2} \text { e } \breve{v} \mathrm{~N}_{\mathrm{o}} \exp \left(-\frac{q e}{4 \pi \varepsilon o r k T}\right)
$$

where qs is a modified saturation charge given by

$$
\mathrm{qs}=4 \pi \varepsilon \mathrm{o}(\mathrm{r}+\lambda)^{2} \operatorname{Eo}\left(1+2 \frac{K-1}{K+2} \frac{(\mathrm{r}) 3}{(r+\lambda) 3}\right)
$$

In which $\mathrm{q}=$ charge, coulombs $\mathrm{C}$

$\mathrm{N}_{0}=$ Free ion density, $\mathrm{N}_{0} / \mathrm{m}^{3}$

$\mathrm{e}=$ electronic charge, Coulombs

$€_{0}=$ Permittivity of free space, $\mathrm{C}^{2} / \mathrm{N}-\mathrm{m}^{2}$

$\mathrm{E}_{0}=$ Electrical Field, $\mathrm{V} / \mathrm{m}$

$\mathrm{b}=$ Ion mobility, $\mathrm{m}^{2} / \mathrm{Vs}^{-1}$

$\breve{v}=$ mean thermal speed of ions, $\mathrm{m} / \mathrm{sec}$

$\mathrm{r}=$ particle radius, $\mathrm{m}$ 


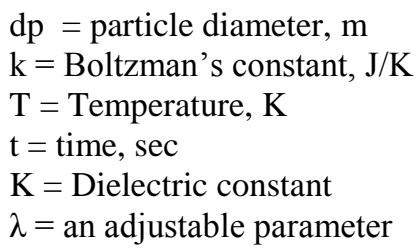

The value of electric field utilized in the estimation of particle charging is the mean value between discharge and collecting electrode. The calculation of local electric field is needed to compute the charged particle velocity near the collecting electrode. Leutert and Bohlen has reviewed the previous work related on the problem and introduced the numerical technique and equations which need to be resolved in two parameters, written in discrete form [3].

$$
\begin{aligned}
& \frac{\Delta^{2} \mathrm{~V}}{\Delta X^{2}}+\frac{\Delta^{2} \mathrm{~V}}{\Delta Y^{2}}=-\frac{\rho}{\epsilon 0} \\
& \rho^{2}=\epsilon O\left(\frac{\Delta V}{\Delta X} \frac{\Delta \rho}{\Delta X}+\frac{\Delta V}{\Delta Y} \frac{\Delta \rho}{\Delta \mathrm{Y}}\right)
\end{aligned}
$$

Where $\mathrm{V}=$ Potential, Volts

$\rho=$ space charge, coulomb $/ \mathrm{m}^{3}$

$\mathrm{X}=$ distance perpendicular to gas flow from wire to plate

$\mathrm{Y}=$ distance parallel to gas flow from wire to wire

Migration velocity results from the coulomb and viscous drag forces following up on a suspended particle are required in estimating theoretical collection efficiency. In addition, acceleration time is neglected in the case of particle size is in the scope of interest and migration velocity is shows below:

$$
\mathrm{W}=\frac{q E_{p C}}{6 \pi r \mu}
$$

where $\quad \mathrm{w}=$ migration velocity of a particle of radius $\mathrm{r}, \mathrm{m} / \mathrm{sec}$

$\mathrm{Ep}=$ electric field near collecting electrode, volt $/ \mathrm{m}$

$\mathrm{C}=$ Cunningham correction factor

$\mu=$ gas viscosity $(\mathrm{kg} /(\mathrm{m} / \mathrm{sec}))$

Calculation of migration velocity shown in Equation 5 is valid for the particle with diameters greater than $4.5 \mu \mathrm{m}$. The value of the corrected migration velocity has been calculated from the fix or relational value of the migration velocity that ranges from $8-11 \mathrm{~cm} / \mathrm{sec}$ (for $\mathrm{w}$ with $\mathrm{dp}>4.5 \mu \mathrm{m}$ ). The expression for the corrected migration velocity is shown below:

$$
\mathrm{w}_{\mathrm{c}}=\mathrm{w}(1.7-0.45 \ln \mathrm{dp})
$$

The range of application of Equation 6 is valid for the particle with diameters in the range $0.2-4.5 \mu$ m. The intitial equation for describing particle collection in electrostatic precipitators under turbulent flow conditions was derived by Deutsch and gives a collection efficiency as a function of gas volume flow, collection area, and migration velocity as follows:

$$
\eta=100\left[1-\exp \left(-\frac{A_{p} W}{Q}\right)\right.
$$


where

$$
\begin{aligned}
& \eta=\text { collection efficiency of a particle of radius } r, \% \\
& \text { Ap = collecting area, } \mathrm{m} 2 \\
& \mathrm{Q}=\text { gas volume flow, } \mathrm{m} 3 / \mathrm{sec}
\end{aligned}
$$

But there are some suppositions which are based on the derivation Equation 7 which are as follows:

a) It has been assumed that the uniform mixing of the particles has been provided by the turbulence.

b) The gas flows with uniform velocity with containing all the particles.

c) The migration velocity is same all over the body of the precipitator irrespective of the size of the particles.

d) The disturbance due to mechanical bodies inside the precipitator is zero [4,5]

White [5] has announced a progression of trials utilizing oil fumes under test conditions that were meet with all the assumptions stated above. The outcomes shows that the Deutsch equation portrays the mechanism accumulation for particulate in an electrostatic precipitator under idealized conditions. The Deutsch equation is shown as follows:

$$
\mathrm{W}_{\mathrm{p}}=\frac{Q}{A} \ln \left(\frac{100}{100-\eta_{o}}\right)
$$

where

$$
\begin{aligned}
& \mathrm{Wp}=\text { migration velocity of particles (uncorrected), } \mathrm{m} / \mathrm{sec} \\
& \eta_{0}=\text { overall mass collection efficiency, } \%
\end{aligned}
$$

\subsection{Corrections to Theoretical Predictions}

There are some non-idealities which bring little modifications into the calculations for the performance of the efficiency of the precipitator. The factors effecting the efficiency of the electrostatic precipitator include the followings;

(1) Gas velocity distribution,

(2) Gas sneakage,

(3) Rapping re-entrainment.

\section{Effect of Gas Velocity Distribution:}

The distribution of the velocities across the EP is not the same and to a great extent the velocity distribution effects the performance of the EP as well. So in order to approximate the possibilities, the common practice adopted in the experiments were to measure the velocities at multiple points across the body of the precipitator. The Deutsch equation have been rearranged to calculate the penetration coefficient which will help us further approximate the solution of the equation for the performance/collection efficiency of the precipitator. This can be accomplished as follows:

1. Calculate a constant $\mathrm{k}$ from the efficiency predicted under ideal conditions

$$
\mathrm{k}=\mu_{a} \ln \frac{1}{1-n / 100}
$$

2. Calculate the mean penetration;

$$
\begin{gathered}
\mathrm{p}=\frac{1}{N \mu_{a}} \sum_{i=1}^{N} \mu_{i}\left(1-\eta_{i} / 100\right) \\
\mathrm{p}=\frac{1}{N \mu_{a}} \sum_{i=1}^{N} \mu_{i} e^{-\frac{k}{\mu_{i}}}
\end{gathered}
$$


where
$\mu_{a}=$ average velocity, $\mathrm{m} / \mathrm{sec}$
$\mathrm{p}=$ corrected penetration fraction of a given size particle
$\mathrm{N}=$ number of points or channels with a given velocity
$\mathrm{ui}=$ point values of velocity
$\eta \mathrm{i}=$ point values of efficiency

The ratio between the original migration velocity to the reduced migration velocity will help us to calculate the non-help of the correction factor. The correction factor "F" may be obtained from:

$$
\exp \left(-\frac{k}{F} \cdot \frac{1}{\mu_{a}}\right)=\frac{1}{N \mu_{a}} \sum_{i=1}^{N} \mu_{i} \exp \left(-\mathrm{k} / u_{i}\right)=\mathrm{p}
$$

Where

$$
\mathrm{F}=-\frac{k}{u_{a}(\ln p)}
$$

\section{Gas Sneakage and Dust Re-Entrainment:}

Gas sneakage happens when gas bypasses the electrified zones of an electrostatic precipitator by moving through hoppers or through the high voltage protection space. Frequent baffles which drive gas to come back to the gas passages between the collection plates can help to lessen the gas sneakage. In the absence of baffles, the lowest possible penetration will established by percent of sneakage that causes of having zero collection efficiency to occur. Therefore, in the present of baffles, the sneakage remixed with part of the fundamental key stream and then re-by-passes in the next of zone with absence of baffle. There are three factors that cause the limitation of penetration due to sneakage which gas sneakage per section amount, remixing degree and the sections number. The expression for the penetration corrected sneakage will be given by

$$
p_{S}=\left[\mathrm{S}+(1-\mathrm{S})(1-\eta / 100)^{1 / N_{S}}\right]^{N_{S}}
$$

where

$$
\begin{aligned}
& p_{S}=\text { Penetration corrected for sneakage } \\
& \mathrm{S}=\text { Fractional amount of gas sneakage per section } \\
& N_{S}=\text { Number of baffled sections } \\
& \eta=\text { Collection efficiency of a given particle size obtained with no sneakage. }
\end{aligned}
$$

Rapping Re-entrainment would be the other factor which will effect the collection efficiency of the electrostatic precipitator [7]. An equation has been developed for this too, similar to the sneakage loss and is given as follows:

$$
p_{R}=\left[\mathrm{R}+(1-\mathrm{R})(1-\eta / 100)^{1 / N_{R}}\right]^{N_{R}}
$$

where

$$
\begin{aligned}
& p_{R}=\text { penetration corrected for re-entrainment } \\
& \mathrm{R}=\text { fraction of material re-entrained per section } \\
& N_{R}=\text { number of stages over which re-entrainment is assumed to occur } \\
& \eta=\text { collection efficiency of a given particle size obtained with no re-entrainment. }
\end{aligned}
$$

This equation is then used for the calculation of the efficiency of the electrostatic precipitator using relation given below: 


$$
w_{C}=\frac{Q}{A} \ln \left(\frac{100}{100-\eta}\right)
$$

A report published by US environment protection agency entitled "Particulate Collection Efficiency Measurement on a Wet Electrostatic Precipitator" shows the used of the model above in the calculation of wet electrostatic precipitator [8]. It was found that the particle size for wet electrostatic precipitator was in a range of $0.2-1.3 \mu \mathrm{m}$ based on the result obtained from the model and the experimental measurements.

\subsection{RESULTS AND DISCUSSION}

The results from simulation using model discussed in Section 2 can be summarized as follows:

\subsection{Effect of Number of Plates}

Figure 5 shows the efficiency of wet electrostatic precipitator by varying the number of plates. It shows that the efficiency of wet electrostatic precipitator varies from $0.1 \%$ to $98.99 \%$ at 5 plates to 500 plates. After 500 plates the efficiency will remain at $99 \%$. This results have been obtained at fixed flow rate and fixed velocity of $167.37 \mathrm{~m}^{3} / \mathrm{sec}$ of $2.5 \mathrm{~m} / \mathrm{sec}$ respectively.

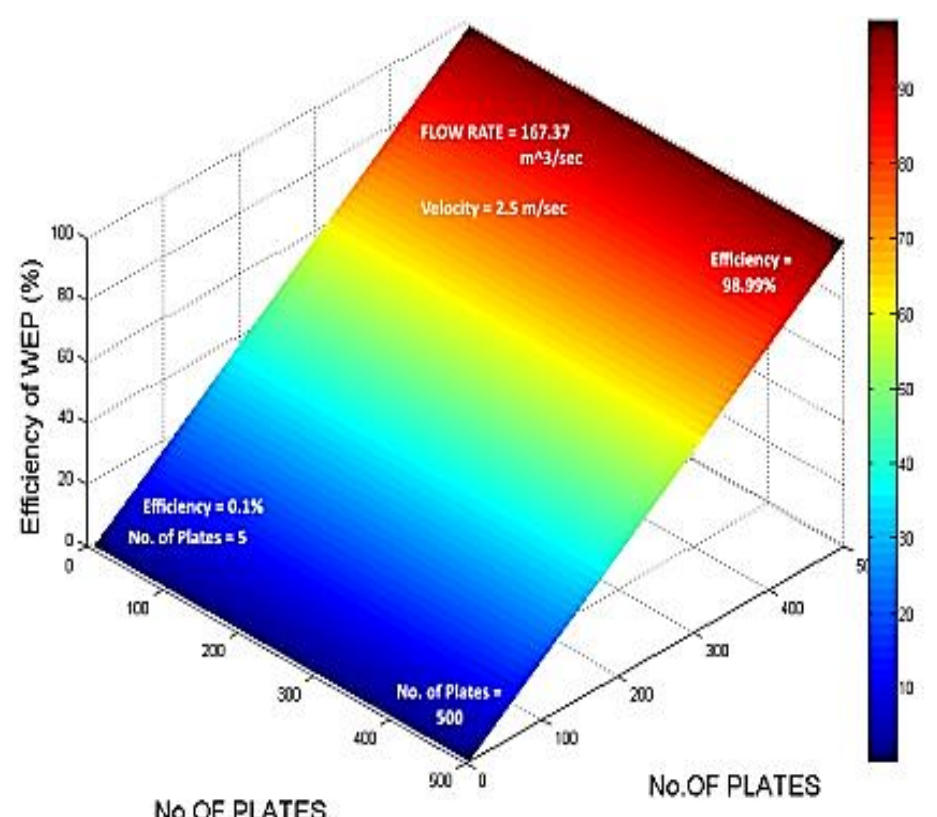

Figure 5. Efficiency of WEP vs No. of Plates

\subsection{Effect of Flow Rate}

Figure 6 shows the effect of flow rates towards the efficiency of wet electrostatic precipitator. It shows that the efficiency varies from $0.5 \%$ to $99 \%$ in between $16500 \mathrm{~m}^{3} / \mathrm{sec}$ to $167.37 \mathrm{~m}^{3} / \mathrm{sec}$ plates respectively. But at a flow rate below $167.37 \mathrm{~m}^{3}$ $/ \mathrm{sec}$ with a fixed number of 500 plated and $3.5 \mathrm{~m} / \mathrm{sec}$ of fixed velocity, the efficiency remain equal to or greater than $99 \%$ plus as due to more time that the applied electric field have for the treatment of the exhaust gas. 


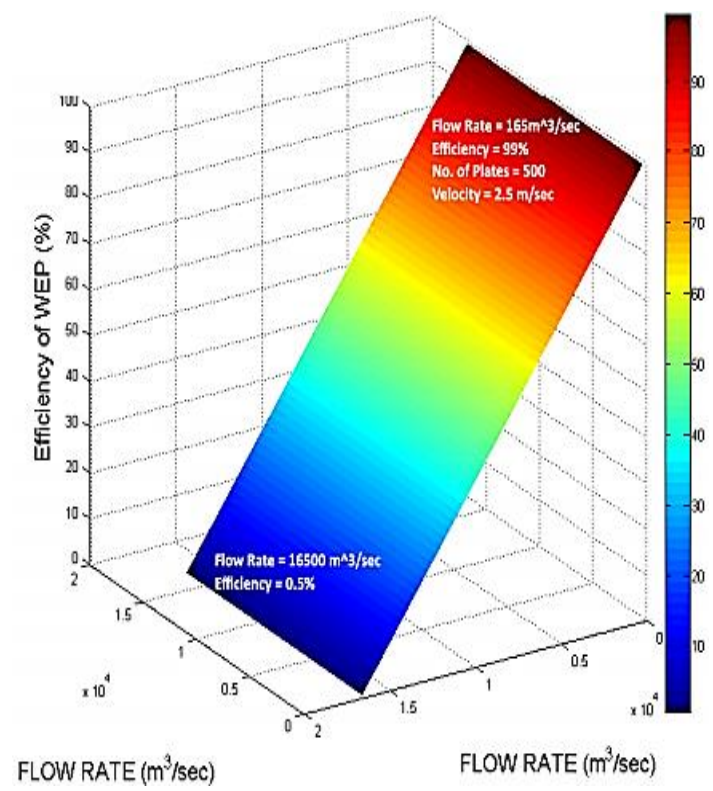

Figure 6. Efficiency of WEP vs Flow Rates

\subsection{Effect of Velocity}

There are three cases in investigating the efficiency of WEP in terms of veloity as follows:

a) At fixed velocity, $2.5 \mathrm{~m} / \mathrm{sec}$

b) Velocity of $2.5 \mathrm{~m} / \mathrm{sec}$ to $3.5 \mathrm{~m} / \mathrm{sec}$

c) Velocity more than $4 \mathrm{~m} / \mathrm{sec}$

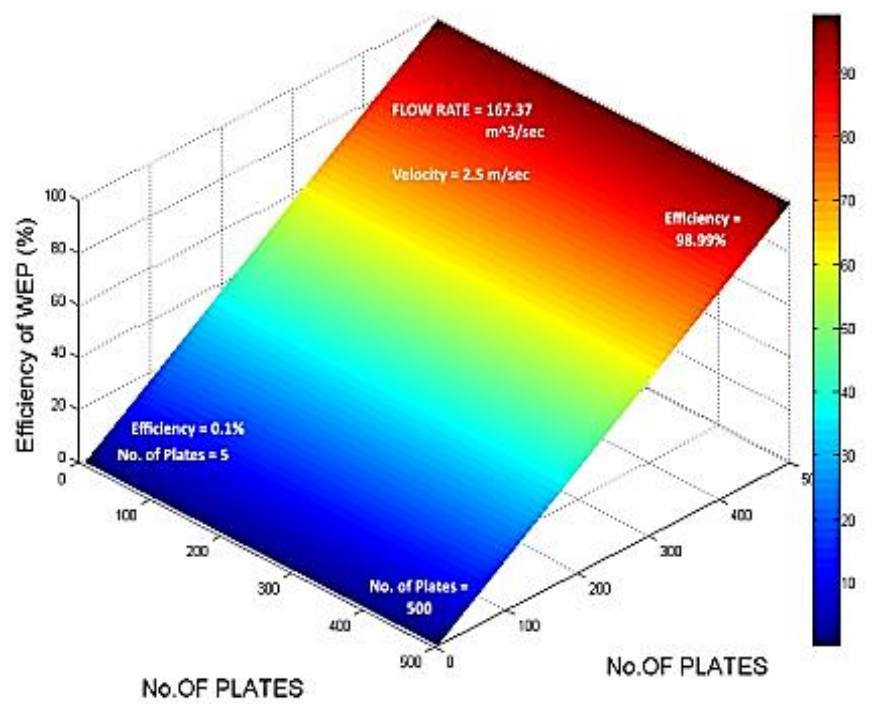

Figure 7. Efficiency of WEP at Velocity of $2.5 \mathrm{~m} / \mathrm{sec}$ in variation of number of plates 


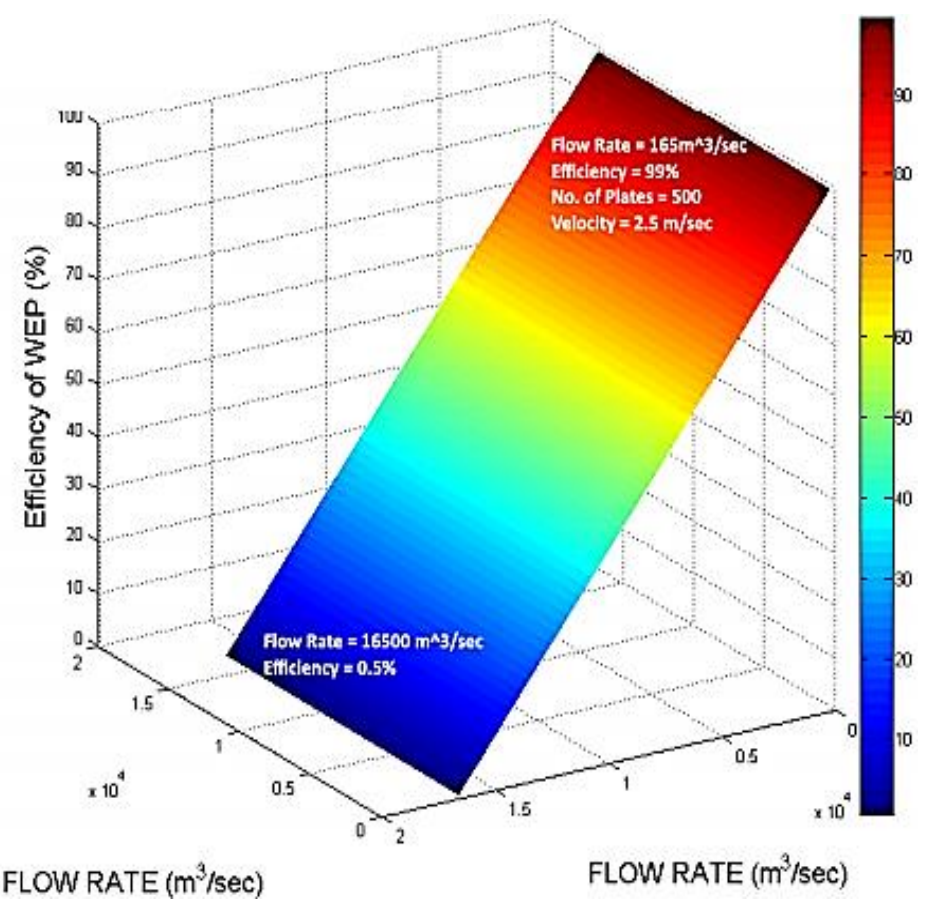

Figure 8. Efficiency of WEP at Velocity of $2.5 \mathrm{~m} / \mathrm{sec}$ at different flow rate

Figure 7 and Figure 8 shows the efficiency of WEP varies from $0.1-98.99 \%$ and $0.5-99 \%$ as for keeping the velocity fixed at $2.5 \mathrm{~m} / \mathrm{sec}$ by varying the number of plates from 5-500 and flow range of $16500 \mathrm{~m} 3 / \mathrm{sec}$ to $167.37 \mathrm{~m} 3 / \mathrm{sec}$.

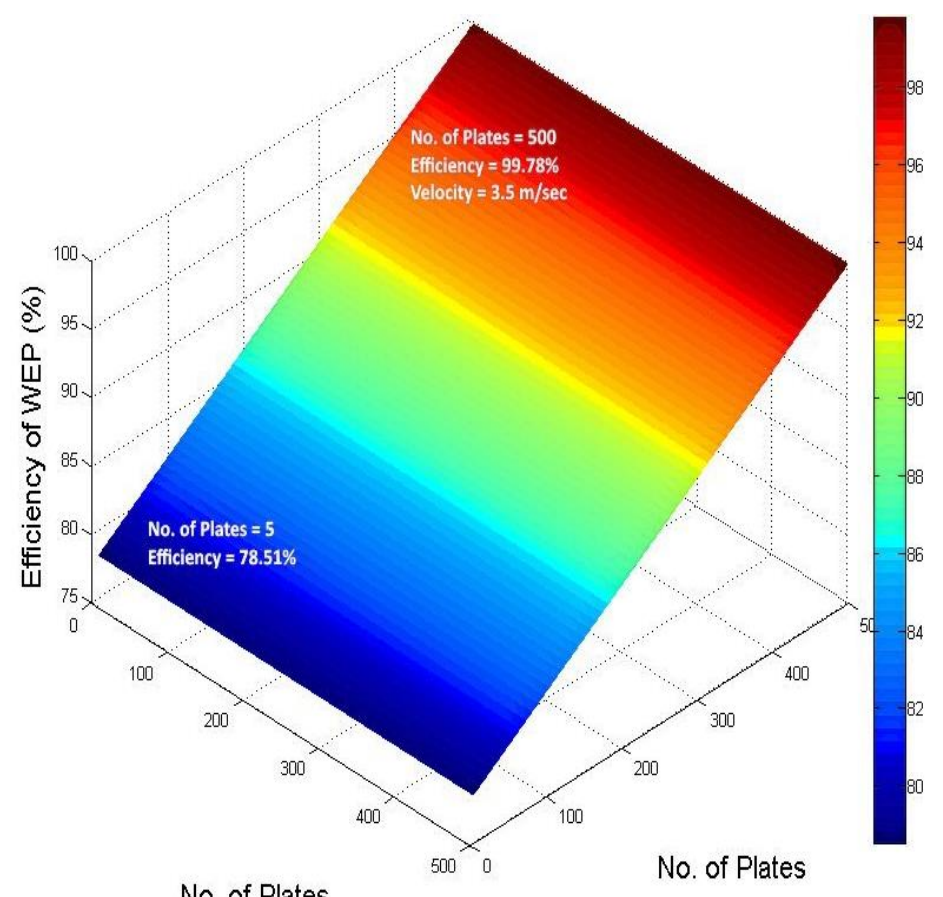

Figure 9. Efficiency of WEP at Velocity from $2.5 \mathrm{~m} / \mathrm{sec}$ to $3.5 \mathrm{~m} / \mathrm{sec}$ at different number of plates

Figure 9 shows the WEP efficiency varies from $78.51-99.78 \%$ in between velocity of $2.5 \mathrm{~m} / \mathrm{sec}$ to $3.5 \mathrm{~m} / \mathrm{sec}$ at number of plates from 5 to 500 . 


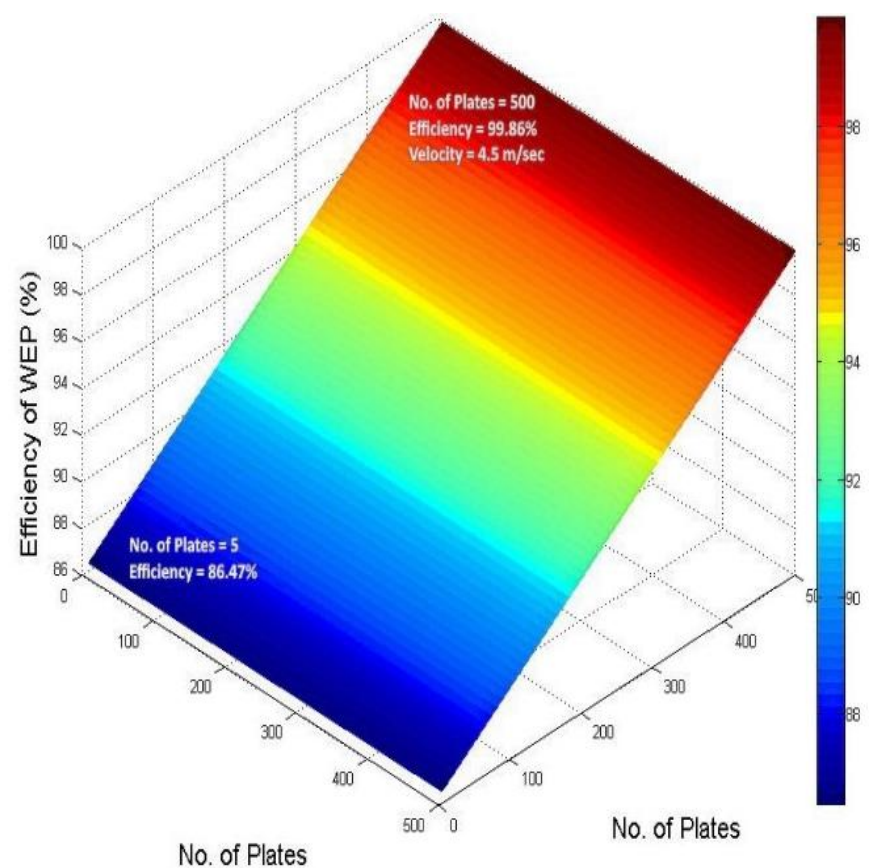

Figure 10. Efficiency of WEP at Velocity from $2.5 \mathrm{~m} / \mathrm{sec}$ to $3.5 \mathrm{~m} / \mathrm{sec}$ at different number of plates

As the velocity has been raised till $4.5 \mathrm{~m} / \mathrm{sec}$, at fixed flow rate of $167.37 \mathrm{~m} 3 / \mathrm{sec}$, the efficiency will vary from $86.47-99.86 \%$ as shown in Figure 10.

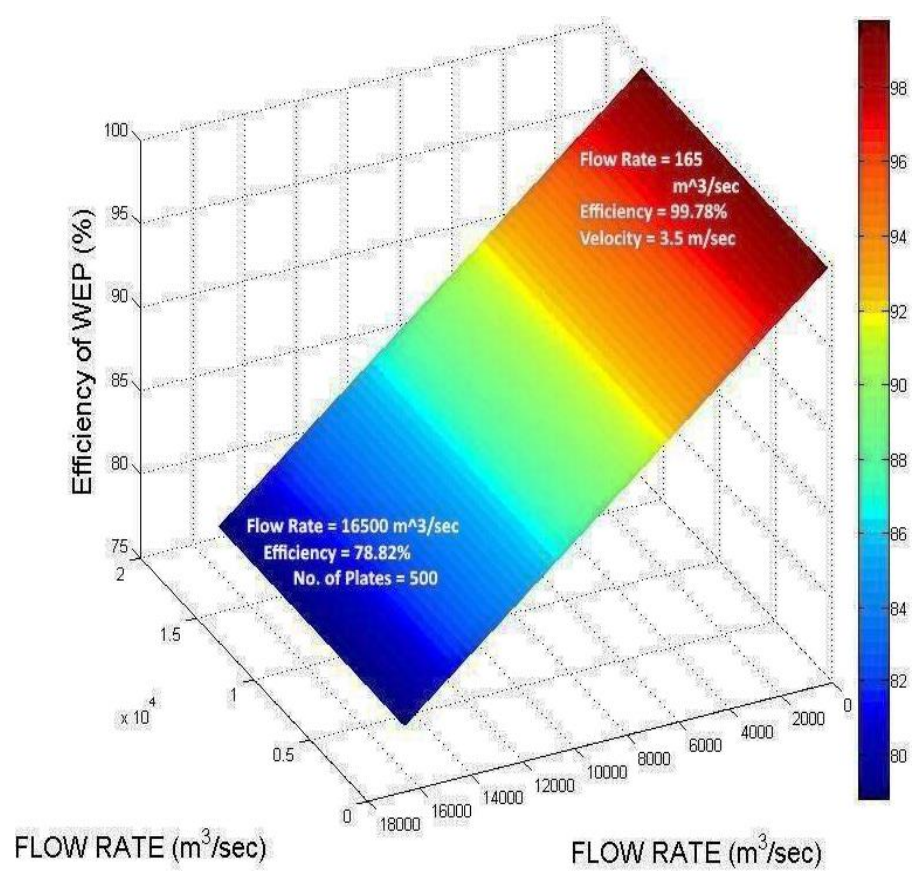

Figure 11. Efficiency of WEP at fixed velocity $(3.5 \mathrm{~m} / \mathrm{sec})$ and number of plates (500 plates) at different flow rates 


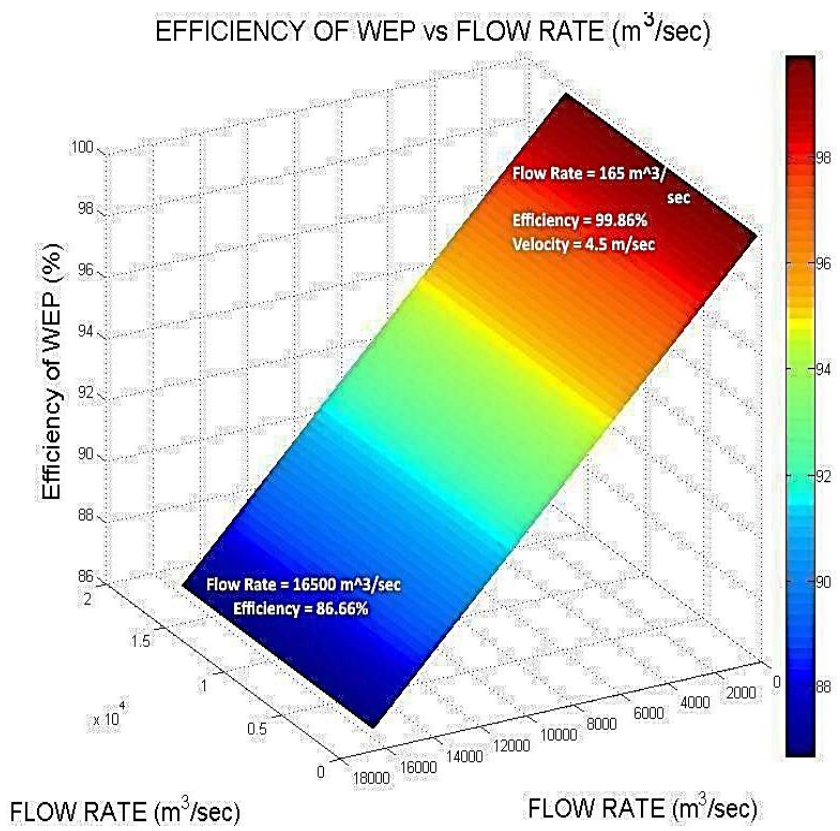

Figure 12. Efficiency of WEP at fixed velocity $(>4 \mathrm{~m} / \mathrm{sec}$ ) and number of plates (500 plates) at different flow rates

Figure 11 and Figure 12 shows the results of WEP efficiency at fixed number of plates (500 plates) and at fixed number of velocity of $3.5 \mathrm{~m} / \mathrm{sec}$ and $>4 \mathrm{~m} / \mathrm{sec}$ respectively. As flow rate is varying from $16500 \mathrm{~m}^{3} / \mathrm{sec}$ to $165.37 \mathrm{~m}^{3} / \mathrm{sec}$ for velocity of $3.5 \mathrm{~m} / \mathrm{sec}$, WEP efficiency is in a range of 78.82 to $99.78 \%$. Therefore, in the case of velocity more than $4 \mathrm{~m} / \mathrm{sec}$, WEP efficiency varies from 86.66 to $99.86 \%$ as shown in Figure 12 .

\subsection{CONCLUSION}

The performance of the electrostatic precipitator in removing the fine particles from the flue gas was measured by varying the number of plates, velocity and gas flowrates of the flue gas by using the model. According to the model, after a certain values of number of plates, velocity and flow rates there is no significant improvement in the performance of the WEP. In addition, the increase in velocity increases the efficiency even at low number of plates and high flow rate where in this type of conditions we expect a very drastic decrease in efficiency of Wet Electrostatic Precipitator (WEP).

\section{Acknowledgements}

The authors would like to thank the Faculty of Engineering, Universiti Malaysia Sarawak for their support on this project.

\section{References}

[1] United States Environmental Protection Agency, 1975. Particulate collection efficiency measurement on a wet electrostatic precipitator. US. Environmental protection technology series. Website: nepis.epa.gov/Exe/ZyPURL.cgi?Dockey=9101MY5I.TXT.Access date: 20 September 2017

[2] W. B. Smith and J. R. McDonald. 1974. "Calculation of the Charging Rate of Fine Particles by Unipolar Ions," presented at Symposium on Electrostatic Precipitators for the Control of Fine Particles, Pensacola Beach, Fla.

[3] Gaylord W. P. 1975. Adhesive Behavior of Dust in Electrostatic Precipitation. Journal of the Air Pollution Control Association. $25(2)$ : $113-117$.

[4] Leutert, G. and B. Bohlen. 1972. The Spatial Trend Of Electric Field Strength And Space Charge Density In Plate-Type Electrostatic Precipitators. Staub-Reinholt. Luft. 32(7): 27-33.

[5] White. H. J. 1963. Industrial Electrostatic Precipitation. Addison-Wesley, Reading, Massachusetts.

[6] Miloua. F., Tilmatine. A., Gouri. R., Kadous. N., and Dascalescu. L. 2007. Optimization Of The Rapping Process Of An Intermittent Electrostatic Precipitator. The European Physical Journal Applied Physics. 41(1): 81-85.

[7] John P. G., and Norman L. F. 1975. A Theoretically Based Mathematical Model for Calculation of Electrostatic Precipitator Performance. Journal of the Air Pollution Control Association. 25(2:) 108-113. 